\title{
A New Laboratory for Hands-on Teaching of Electrical Engineering
}

\author{
Andrea Cavagnino, Senior Member IEEE, Gianmario Pellegrino, Senior Member, IEEE, \\ Abouzar Estebsari, Member, IEEE, Eric Armando, Member, IEEE, and Radu Bojoi, Senior Member, IEEE \\ Politecnico di Torino, Dipartimento Energia \\ Corso Duca degli Abruzzi, 24 - 10129, Torino - Italy \\ andrea.cavagnino@polito.it, gianmario.pellegrino@polito.it, abouzar.estebsari@polito.it, eric.armando@polito.it, radu.bojoi@polito.it
}

\begin{abstract}
This paper describes an innovative laboratory for students in Electrical Engineering courses, which is recently established at the Energy Department of Politecnico di Torino, Italy. The main peculiarities of the lab are the high ICT content of each test rig, the multidisciplinary experiences, and the handson teaching methodology, allowing the student to have access in overall safety to many complex electrical/ electromechanical systems. Currently, eight courses of Bachelor and Master of Science degrees in electrical engineering carry out in-class exercises and hands-on experiments in the new lab, serving over 200 students in total per year. The innovative lab also allows for external collaborations with companies and institutions for specific (and in some cases permanent) training offers, like a oneday per month LabVIEW course for faculty and staff members of Politecnico di Torino.
\end{abstract}

Keywords-Electrical engineering, hands-on laboratory, multidisciplinary, student motivation and satisfaction, electrical circuit theory, power system, electrical machines and drives, power electronic, control, measurement and data acquisition.

\section{INTRODUCTION}

In 1889 Galileo Ferraris founded the School of Electrical Engineering, the first in Italy, at the Royal Italian Industrial Museum. At that time, Galileo Ferraris well represented Italy in the emerging 'electrical world' constituted by exceptional scientists, such as Nikola Tesla and George Westinghouse. The legacy of Galileo Ferraris still remains in the research and teaching carried out at Politecnico di Torino; in fact, in 2018 the "electrical and electronic engineering" sector has been ranked as the second in Italy, the thirteenth in Europe, and the fiftieth in the world [1].

The teaching quality is regularly monitored by Politecnico di Torino with a student interview-based system called $\mathrm{CpD}$ (i.e. the Italian acronym for 'Comitato Paritetico della Didattica', translated in 'Joint Committee on Teaching', [2]). The on-line questionnaire form, available for filling in the last two weeks of each course, includes evaluation of the course content, organization and teacher skills. In particular, one of the queries proposed to the students deals with the quality of infrastructures and laboratories.

For the courses specifically dealing with electrical engineering topics, the students, in the past, remarked some deficiencies in the laboratories where they could directly carry out practical works. However, it is important to observe that 'demonstrative' laboratories have been generally available in the framework of many Electrical Engineering courses 'to see' practical aspects of the theoretical concepts presented during the lectures and seminars. However, in these kinds of laboratories, students have not had hands-on experiences on hardware, mainly due to hardware limitation and safety reasons when high voltage industrial apparatus and systems are intended to be used. In these cases, the experiments are conducted by the teachers and technical staffs, leading to a quite passive learning, which in some cases, even misses the practical aspects of the experiment setup [3], [4]. A more active learning allowing for basic understanding of complex principles and concepts related to specific topics could be pursued with multimedia tools, tutorial and, in particular, simulations [5]-[7].

\section{A. Related works}

Towards the so-called active learning, there have been some implementations of laboratories for electrical engineering education. In [8], P. Shekhar and M. Borrego presented an experience of active learning in electrical engineering workshops by reporting instructors' and students' responses to the active learning exercises. The classroom featured an auditorium-style seating arrangement; spaces between the semicircular rows allowed the instructor to move around the classroom and monitor the students' work. Presented tools could be very effective in cases of staff or instructor shortages. T. A. Giuma et. al in [5] described a multimedia platform developed as a teaching tool for circuit and electronics laboratories. This platform integrates some toolbox like Pspice with incorporating sound, graphics and animations to increase learning speed and improve comprehension. D. Millard et. al implemented web-based interactive learning modules (ILMs) integrated with educational multimedia technologies at Rensselaer Polytechnic Institute [6]. The developed platform was a means to capture, review and process a student's actions through providing Internet access to instrumented experimentation and data gathering. The experiments carried out based on this platform are more related to circuits and electronics including filters $\mathrm{CAD}$ and op-amps CAD. M. Travassos Valdez et. al in [7] introduce a desktop virtual reality system for electrical engineering teaching, especially related to 
circuit theory systems practices, in the context of active learning. They created a 3D lab environment for manipulating instrumentation and monitoring measurements for power system and electric machines. The main idea of this set-up was to benefit the communication between teachers and students and among themselves. In other words, this laboratory mainly aims support e-learning for electrical engineering. In addition to active learning solution, some laboratories integrated simulation software and experimental hardware to improve educational results, yet some miss a combination of both. In [9], Ch. Nwankpa et. al presents experiments and implementations of Drexel University's 'Interconnected Power Systems Laboratory" for small scale energy management systems. The lab is a user-friendly computer-controlled power system environment for experiments on fault analysis, load flow, symmetrical components of network, etc.

In [10], A. Al-Ataby proposes a number of novel teaching tools to encourage electrical and electronics engineering students and to attract their attention to the lessons in large multicultural attendance, without feeling insolated and unmotivated. Some of the used tools include virtual lab, mobile applications, on-line tests and exercises, and real-time texting and voting. In these large multicultural cohorts of students, practical works may not be feasible to perform, hence simulation and virtual tools support teaching purposes. However, on the other hand, their adoption of simulations in lectures without the support of laboratory experiments is still under a controversial discussion [11]. In fact, it is worldwide recognized that practical works carried out directly by the students lead to tangible positive results not only related to the fundamental understanding, but also in their motivation to approach the whole course of study [3], [4], [12]-[19]. However, as outlined in [19] for case of studies related to the distribution network protection topics, the best learning option is to find the proper mix between the simulations and laboratory work. One of multi-cast laboratory set-up for training and education purposes is integrating real-time simulation for distribution network control and management through pure simulation, software in-the-loop (SIL), or hardware in-the-loop (HIL). Authors in [21] present a developed interdisciplinary framework for real-time simulations and HIL experiments based on Internet-of-Things approaches which integrates several workstations in a network through TCP/IP or UDP IP communication protocols in a plugand-play, modular, and flexible fashion.

\section{B. Highlight of the developed lab novelty}

In most of aforementioned teaching methods and implementations, there are following commonalities: using multimedia tools, emerging multi-cast simulation platforms, and integration of communication network for monitoring and supervising students as well as data acquisition systems. In some laboratories performing hands-on practices for a specific course (e.g. power electronics) is also foreseen, and in some set-ups only simulation toolboxes are provided. For instance, authors in [18] present a functioning small-scale power network designed as a microgrid by converting an old machine lab for hands-on experiments of students, but the lab is specifically designed for a one-credit hour lab course in undergraduate level.
TABLE I

COMPARISON AMONG SOME OF INNOVATIVE LABORATORIES

\begin{tabular}{|c|c|c|c|c|c|c|}
\hline Reference & \begin{tabular}{|l|} 
Multi- \\
media and \\
Active \\
Learning \\
\end{tabular} & $\begin{array}{l}\text { Software } \\
\text { Simulation }\end{array}$ & $\begin{array}{c}\text { Hands-on } \\
\text { Experiment }\end{array}$ & $\begin{array}{c}\text { Not limited } \\
\text { to single } \\
\text { course }\end{array}$ & $\begin{array}{l}\text { Interdisciplinary } \\
\text { Application }\end{array}$ & $\begin{array}{l}\text { Not limited } \\
\text { to electrical } \\
\text { engineering }\end{array}$ \\
\hline [3] & $\checkmark$ & $\checkmark$ & $\checkmark$ & $\checkmark$ & $x$ & $x$ \\
\hline $\begin{array}{c}\text { [5], [9], } \\
{[11],[20]}\end{array}$ & $\checkmark$ & $\checkmark$ & $x$ & $x$ & $x$ & $x$ \\
\hline $\begin{array}{c}6],[7], \\
{[10],[15]}\end{array}$ & $\checkmark$ & $\checkmark$ & $x$ & $\checkmark$ & $x$ & $x$ \\
\hline$[12]$ & $x$ & $\checkmark$ & $\checkmark$ & $x$ & $x$ & $x$ \\
\hline [13] & $\checkmark$ & $\checkmark$ & $\checkmark$ & $x$ & $\checkmark$ & $x$ \\
\hline [17] & $\checkmark$ & $\checkmark$ & $\checkmark$ & $x$ & $x$ & $\checkmark$ \\
\hline [18] & $x$ & $\checkmark$ & $\checkmark$ & $x$ & $x$ & $x$ \\
\hline OURS & $\checkmark$ & $\checkmark$ & $\checkmark$ & $\checkmark$ & $\checkmark$ & $\checkmark$ \\
\hline
\end{tabular}

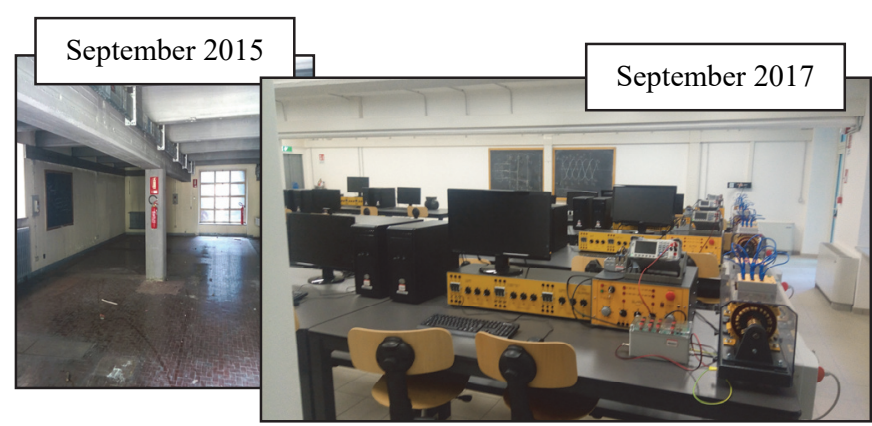

Fig. 1 The new multidisciplinary hands-on laboratory of the Electrical Engineering programs.

In Table I, a comparative overview of some of other laboratories introduced in literature with respect to our developed lab is provided in order to highlight novelty and features. In our laboratory, we are aiming at pooling together most of these features in one integrated lab; this lab enables a wide range of practices from pure software simulation to hands-on experiments using small energy scale machines and physical devices, data acquisition system, etc.

All work bench set-ups are interconnected through an integrated ICT supported network. The lab also provides performing practices for several electrical and non-electrical courses. This may seem very important from cost-benefit perspective for establishing educational laboratories meeting capacity requirement of courses with large number of trainees and students; but what highlights the novelty and added value of this set-up, in this regard, is the multidisciplinary capability of our lab enabling concurrent analysis of different electrical and non-electrical engineering subjects through both simulation and experiment.

On the basis of the aforementioned arguments, and scheduled renovations of the spaces and infrastructure for the department's laboratories, the Electrical Engineering Council at Politecnico di Torino decided to start with a hands-on laboratory project, now entitled to the recently deceased colleague prof. Riccardo Tommasini. The renovations started in 2015 , while the laboratory was partially operative since fall 2016, and accomplished for the 2017/2018 academic year - see Fig. 1. 
TABLE II

BaCHELOR PROgRam IN EleCtrical ENGINEERING: COURSES WITH PRACTICAL WORKS IN THE HANDS-ON LABORATORY

\begin{tabular}{|c|l|c|c|}
\hline $\begin{array}{c}\text { Year - } \\
\text { Period }\end{array}$ & Course & ETCS & Type \\
\hline II - 1 & Electrical circuits and network analysis & 10 & Obligatory \\
\hline III - 1 & Electrical measurements & 6 & Obligatory \\
\hline III - 1 & Electrical machines & 12 & Obligatory \\
\hline III - 1 & Fundamental of power electronics & 10 & Obligatory \\
\hline III - 2 & Electrical system and safety & 12 & Obligatory \\
\hline III - 2 & Fundamental of electrical drives & 10 & Obligatory \\
\hline
\end{tabular}

TABLE III

MSC Program IN ELECTRICAL ENGINEERING: COURSES WITH PRACTICAL WORKS IN THE HANDS-ON LABORATORY

\begin{tabular}{|c|l|c|c|}
\hline $\begin{array}{c}\text { Year }- \\
\text { Period }\end{array}$ & Course & ETCS & Type \\
\hline I -1 & Applied electromagnetism & 10 & Obligatory \\
\hline I -1 & Electrical machine II & 10 & Obligatory \\
\hline I -2 & Electrical drives & 10 & Obligatory \\
\hline I -2 & Power systems & 10 & Obligatory \\
\hline II -1 & Electric power distribution and utilization & 10 & Obligatory \\
\hline II -1 & Electrical energy static conversion & 10 & Obligatory \\
\hline II -1 & Smart electricity systems & 8 & Optional \\
\hline II -2 & $\begin{array}{l}\text { Electrical plant design } \\
\text { Power system economy } \\
\text { Applied control of electrical drives } \\
\text { Propulsion of hybrid and electric vehicles }\end{array}$ & 8 & $\begin{array}{c}\text { Obligatory } \\
/ \\
\text { Optional }^{\text {a }}\end{array}$ \\
\hline
\end{tabular}

a. depending on the student career: Electrical Energy Conversion or Electrical Energy Systems program.

In the next section, an overview of our electrical engineering program is provided. In Section III, the novel laboratory evolution from design to implementation and management is presented, and in Section IV, the laboratory setup and facilities entitled "Micro-Grid Project" is discussed with some level of details. In Section V, some hardware equipment and possible applications of the lab are discussed, and in Section VI, a conclusion with remarks is provided.

\section{Electrical EngineEring Program Overview}

In accordance to the Bologna process, the Electrical Engineering Program is structured in a 3-years Bachelor's degree and a 2-years Master's degree. Complete details about the career programs can be found in [22] and [23], nevertheless in Table II and Table III the courses which require a hand-on laboratory that were initially considered to design a multidisciplinary infrastructure are listed. In these tables, the courses highlighted in grey are those which had already been using the hands-on laboratory. In addition to the courses offered to the Electrical Engineering students, the Tommasini's Laboratory have been already used for two courses of different degree programs:

- "Introduction to electrical engineering/electrical machines" course during the third year, first semester of the Bachelor program in Mechanical Engineering;

- "Power generation from renewable sources" course at the second year, first semester of the Master program in Energy and nuclear engineering.

These two opportunities proved the possibility to host larger cohorts of students (the aforementioned courses count more than 100 students) in the lab, scheduling adequate number of sessions for each practical work.

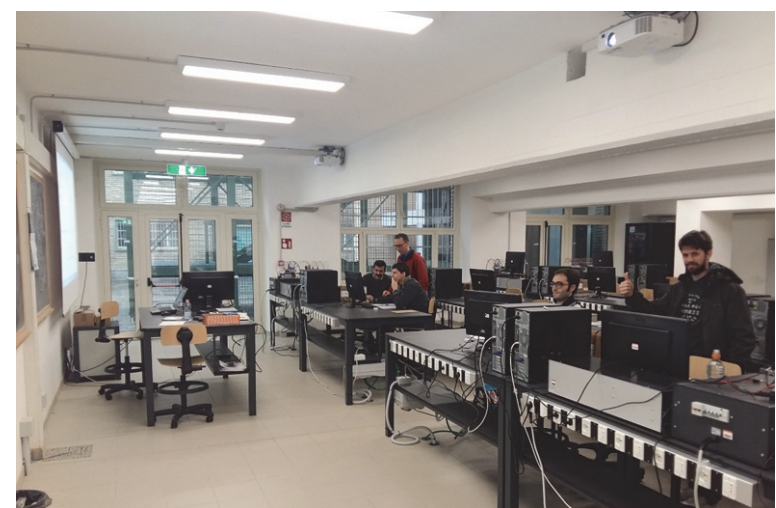

Fig. 2 The first training LabVIEW course: core 1, February 8th, 2017.

With respect to the courses related to the bachelor programs, one might ask what the real need is to commit resources to hands-on laboratories instead of proceeding with the classic numerical simulations or calculation exercises. In addition to the obvious reason that real complex concept knowledge and creative thinking are enhanced 'touching by hands' experiments, practical works offer the way to significantly motivate the bachelor's student. In particular, they are no longer only considered as numbers, as it usually happens in the fundamental courses during the first years [3].

Please note that in the present programs of the Electrical Engineering at Politecnico di Torino, 'pure' lab courses (i.e. course whose focus in instructing experimental works without detailing theoretical background) or project-based learning are not currently planned.

\section{DESIGN, IMPLEMENTATION AND MANAGEMENT OF THE HANDS-ON LABORATORY}

Based on the numbers and items in Table I and Table II, all the course topics can be substantially grouped in four main fields: power systems, electrical machines, drives \& control, and measurements \& data acquisition. With the need to limit the costs, the initial problem was to find a suitable framework in which the aforementioned majors of electrical engineering were covered. As articulated in Section IV, the solution was found in the Micro-Grid project, conceptually depicted in (Fig. 4). The selected structure also guarantees the right multidisciplinary behavior for the new laboratory. In fact, the project's aim was to extend equipment and instrumentations of the experimental laboratory of basic electrical materials to gradually arrive at an advanced experimental laboratory for the study of electricity applications, where loads and generators are placed in a small-scale electricity grid (Micro-Grid). For example, the Microgrid laboratory will allow the study of the conversion and generation of electricity for numerous subjects of the three-year and master's degree in electrical, mechanical, energetic and nuclear engineering. The practices provided to the students include applications in direct and alternating current, single-phase and three-phase, electrical transformers, rotating electrical machines and various electric linear loads. Under the supervision of the teacher and the staff, the students prepare and conduct the experiments, making observations and measurements or data acquisition. 


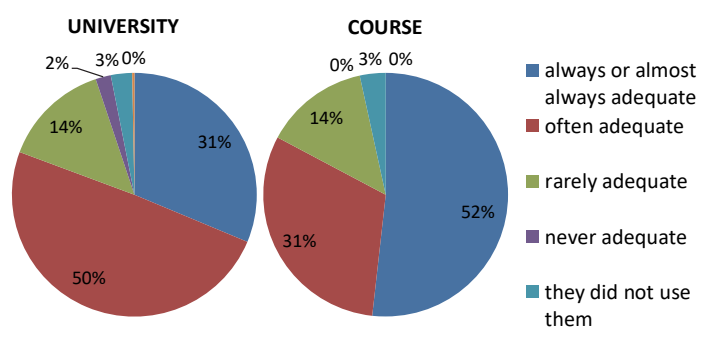

Fig. 3 Satisfaction for the used infrastructures by the 2016 graduated students in Electrical Engineering compared to the average level of the University [24].

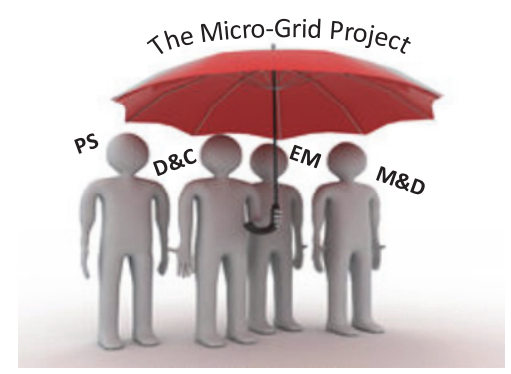

Fig. 4 Micro-Grid project coverage: PS $=$ Power System, D\&C: Drives \& Control, EM=Electrical Machines, M\&D=Measurements \& Data Acquisition.

The technological laboratory counts eight work benches and it was designed for a maximum occupancy of $32-35$ students, allowing to manage the whole Electrical Engineering cohort with two sessions for each in-class exercise subject. The laboratory is equipped with analog-digital acquisition tools interfaced with the computer through LabVIEW. The availability of these advanced data acquisition systems, and the recent agreement with National Instrument, opened the way for 1-day/month LabVIEW training course for faculty and staff of Politecnico di Torino (Fig. 2).

One aspect worth to be remarked is that the lab has been updated every year thanks the funding annually granted by the university (approximately $40 \mathrm{k} € /$ year) for advanced didactical projects, without the need to complete the hardware purchase just in one single step. For example, for the next course of Electrical circuits and network analysis (Table I) the eight work benches will be equipped with conventional digital oscilloscopes. For the startup of the laboratory, the hardware setup and the preliminary verifications, 1-year position for a lab technician have been opened in spring 2017. The staff has been recruited thanks of a crowdfunding among 23 faculty involved both in the Bachelor's and Master's degree courses of Electrical Engineering, proving their real interest in the initiative. In fact, the Tommasini's laboratory is assumed of strategic importance to enhance the teaching quality and the student learning skills.

From this viewpoint, in accordance to the Almalaurea interview, the Electrical Engineering students graduated in 2016 (noting that this cohort did not use the Tommasini's Laboratory yet) were already satisfied of the laboratory infrastructures, as shown in Fig. 3, with respect to the average university level [24]. In the near future, both the $\mathrm{CpD}$ and the Almalaurea interview results will be a very important metric to statistically verify the expected increase in satisfaction of the students who actually use the technological laboratory.

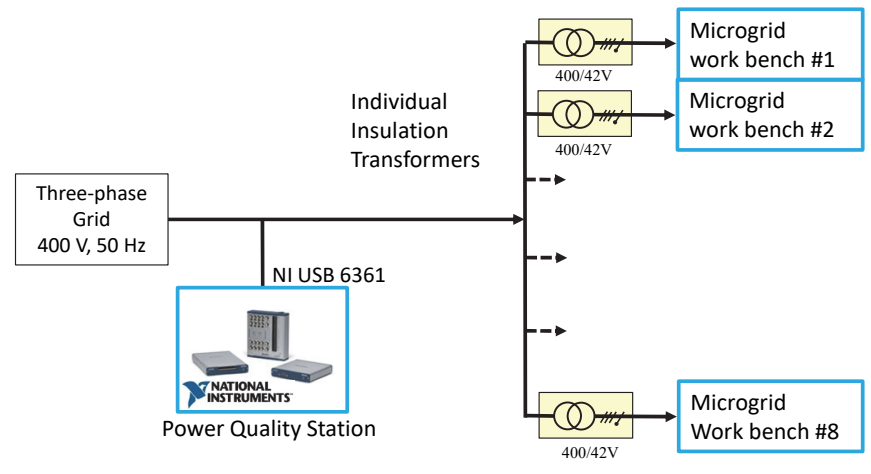

Fig. 5 Functional diagram of the Microgrid laboratory.

\section{The Micro-Grid ProJeCt}

Micro-Grid advanced laboratory will allow the experimental study of a vast number of applications related to the electricity generation, conversion and utilization, the use of renewable energy resources (e.g. photovoltaic and wind) and the management of these resources together with accumulation technologies for the network (e.g. batteries, fuel cells) and for vehicles (e.g. batteries, supercapacitors).

This makes an interdisciplinary analysis opportunity as well as multi-purpose application capability of the lab for different engineering sectors and majors; for example, studying conversion and storage systems allows synergy with different courses involving renewable energy resources (e.g. in energy and nuclear engineering programs), or involving traction systems (e.g. in mechanical engineering or automotive engineering).

The functional diagram of the Micro-grid laboratory is shown in Fig. 5 and contains: (i) a power quality analysis workstation, and (ii) eight individual local set-ups (i.e. MicroGrid work-bench).

A single work-bench (described in Fig. 6) presently allows for the experimental activity related to the following subjects and applications:

- Electrical engineering and electrical machines

- Electrical systems and security

- Electric drives and propulsion systems for electric vehicles

- Micro-Grid control

Integrating further objects planned for future developments (colored in pink in Fig. 6) allows for performing the following additional subjects:

- Generation of energy from renewable resources

- Static conversion for energy generation

- Wireless power transfer

The CAN network automates the Micro-grid and manages the flow of communications and acquisitions. The active front end block regenerates to the three-phase network any power generated continuously from renewable sources (photovoltaic panel or $a c$ machine used by a generator, emulates wind power generation). 


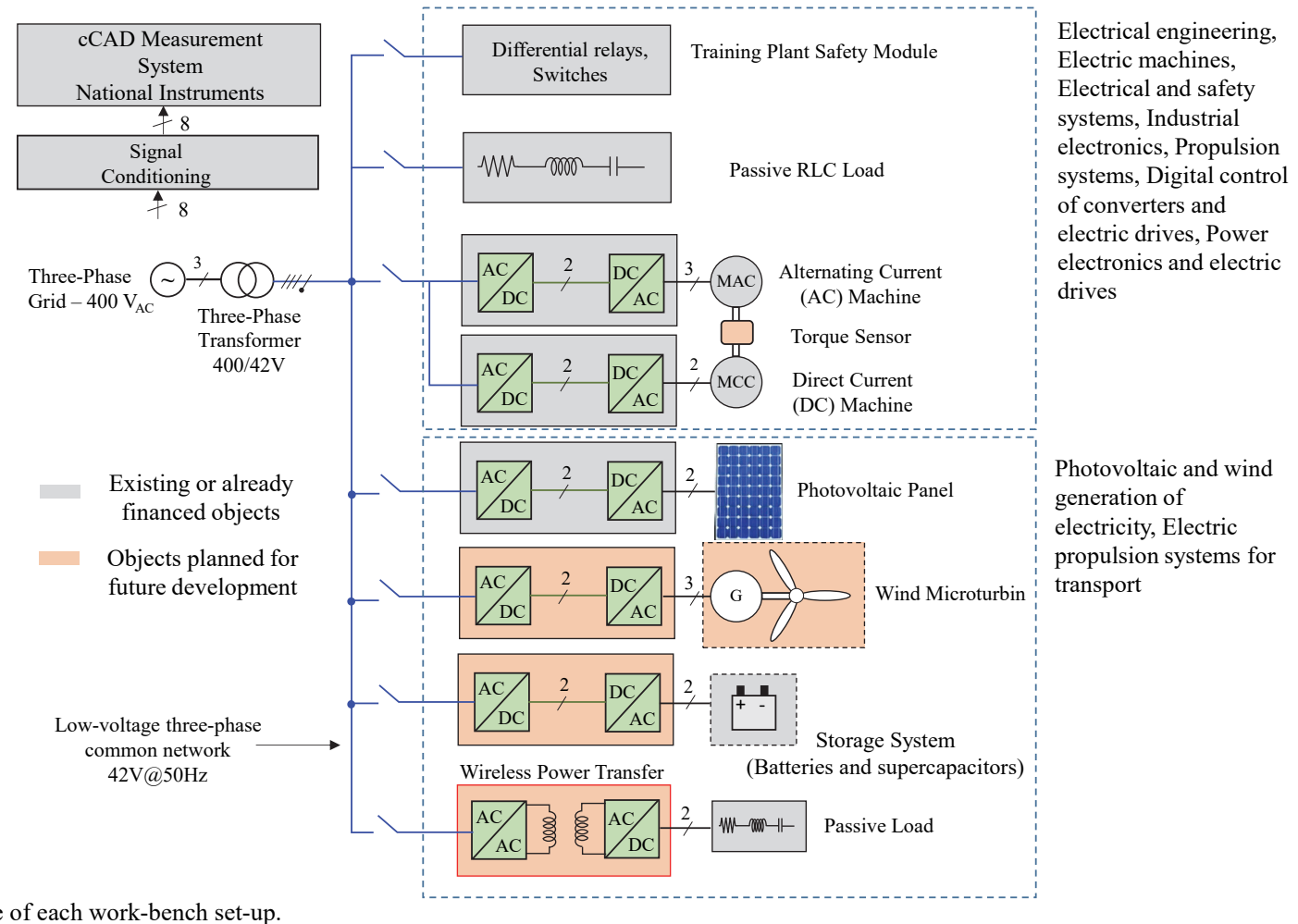

Fig. 6. Scheme of each work-bench set-up.

The servo drive is used to drag the machines under test at impressed speed, or to impose a controllable braking torque. This is useful both for testing electrical machines and for emulating wind generation. STM32 Nucleo technology is a series of devices for the development of real-time control code on the industrial microcontrollers of the STM32 family. Thanks to the collaboration with ST-Microelectronics, the laboratory will have $d c / a c$ and $d c / d c$ converters which can be controlled with STM32 digital cards. Development and debugging software is free.

\section{OVERVIEW OF THE LAB HARDWARE AND APPLICATIONS}

This section shortly summarizes the hardware facilities installed in the lab and some of their applications. As shown in Fig. 7 each work bench is equipped with two large desks, with some free space, and two personal computers: the first one is dedicated to simulations, while the second one is configured for measurement acquisitions. Looking in greater detail at the hardware installed in the desks, by Fig. 8 it is possible to see:

(a) The electrical motor test rig: it is constituted by two 'backto-back' connected rotating machines. The low power, low voltage electrical machines can be selected combining $d c$ machine, asynchronous machine (having squirrel caged or wound rotors); the wound rotor can be supplied with $d c$ current obtaining synchronous operations. Single-phase and three-phase transformers (not shown in Fig. 8)

(b) The $a c \& d c$ supply sources: fixed or a variable single- and three-phase sources are available. In addition to three-phase diode rectifiers to create the $d c$ voltages, $d c / d c$ four quadrants with analog control for teaching purpose will be available soon.

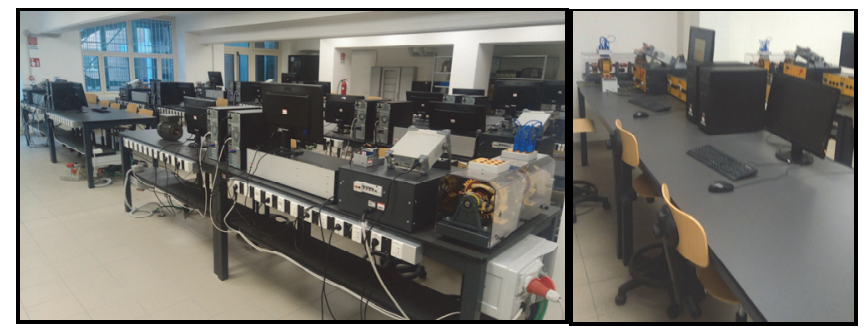

Fig. 7. The eight work benches of the Tommasini's laboratory (left), and the bench view (right).

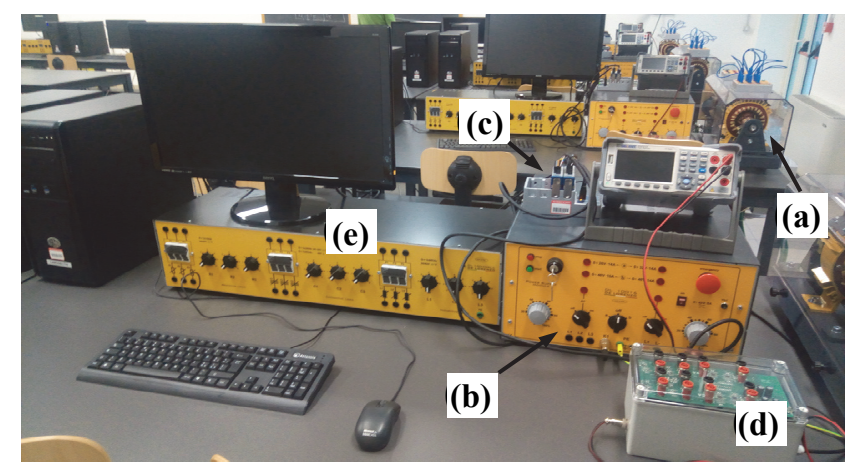

Fig. 8. Bench setup: (a) electrical machines test rig, (b) multi functionalities ac \& dc supply sources, (c) acquisition boards, (d) 4-voltage and 4-current measurement channels, (e) single- and three-phase variable R-L-C loads.

(c) Acquisition boards (NI 9221 and NI 9215) allowing for the use of LabVIEW for the development of virtual instruments. In the near future the acquisition hardware will also consist of NI Virtualbench VB-8034 Oscilloscopes, alternatively of eight Picoscope 3000. 
(d) Signal conditioning box for voltage-current measurements: the boards for the signal conditioning have been designed and produced at the authors' institution. Through eight 'fast' connectors, 4 input-exit amperometric channels and 4 differential voltage channels can be easily wired.

(e) Single- and three-phase variable R-L-C loads.

Additional hardware equipment are:

1) Electric drives (Fig. 9): for this subject, ten automotive brushless motors and twenty industrial brushless ones are available. Two different options to control the drives are also possible: (i) STM32 Core Cards plus ST X-Core Inverter (60 V dc - $15 \mathrm{~A}$ RMS), and virtual oscilloscope via ST-Link, or (ii) the $580 \mathrm{~W}$ Microphase servo-drive plus the graphical LabVIEW interface using the Mod-bus/S-Net communication protocol.

2) Power quality: the laboratory is equipped for measurements on the Power Quality of the industrial voltage network see Fig. 10. The non-linear loads connected to the main are the laboratory PCs.

Last but not the least, it is important to mention that in the laboratory PCs several software tools for advanced simulations are available. For example, for Power system analysis the Neplan toolbox is provided for over 25 users with capability of simulating grids with maximum 50 nodes, allowing for ex-ante analysis before the real experiments for comparison purposes.

\section{AN EXAMPLE OF LABORATORY PRACTICAL WORKS}

Among several variant laboratory practical works developed and carried out in the Tommasini's laboratory during last two years, an example of a hands-on in-class exercise is briefly presented in this section as it is not possible to provide a survey of all practical works in this paper.

This practical work relates to a fundamental course on Electrical Machines for the Bachelor's degree in Electrical Engineering, which was greatly appreciated by the students of the last course. There are four exercitations dealing with:

1) Single and three-phase transformers: equivalent circuit parameter determinations by standard measurements, in-rush currents, not symmetrical three-phase working conditions, and the homopolar flux effects;

2) The $d c$ machine: parameter measurement, torque / speed characteristics determination for series and separated field excitation, constant-torque and constant-power speed regulation, motoring and generating mode analyses;

3) The three-phase asynchronous motor either squirrel cage or wound rotors: equivalent circuit parameter determinations by standard measurements, rotor voltage and current measurements, generator mode analysis, de-energizing test (an example is demonstrated Fig. 11 where measurements and simulation results can be concurrently compared);

4) Synchronous wound field generator: parallel of the alternator to the grid, active and reactive power regulations, load angle measurements, V-curves determination.
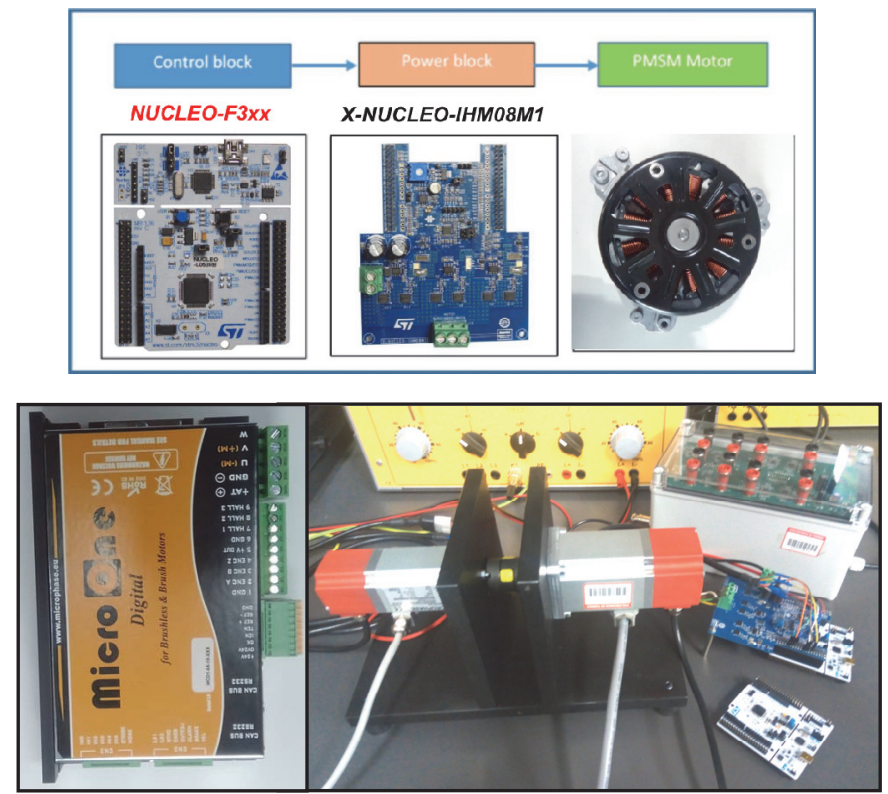

Fig. 9. Two different set-up for electric drives studies: control by microcontroller and power board or by LabVIEW programming of industrial drive.

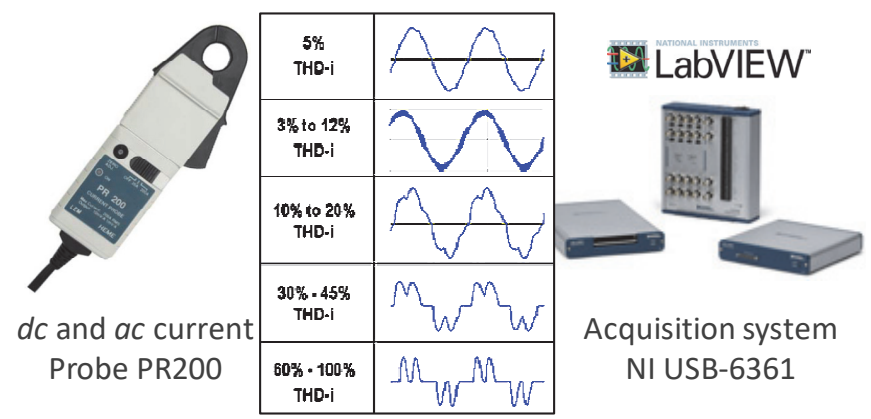

Fig. 10. Equipment for power quality

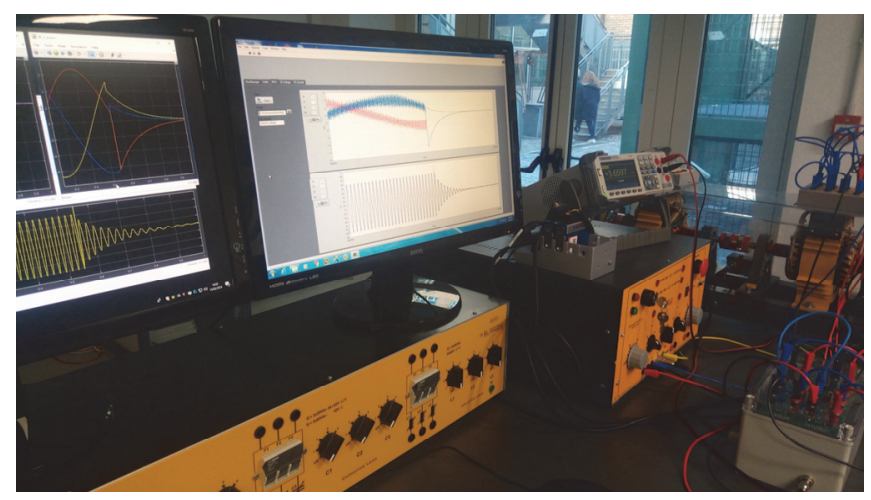

Fig. 11 De-energizing test of induction motor: simulation results (on the monitor on the left) and acquisitions by the virtual NI scope (on the right).

For each exercise, subdivided in two separate sessions, a short description note of the experiment preparation and execution is provided to the students. The student is requested to fill a laboratory report with the measurement results, for post data elaboration. 


\section{CONCLUSION}

An innovative laboratory for hands-on experiments is introduced for Electrical Engineering education. This laboratory is very flexible for energy conversion multidisciplinary studies, and it is highly enhanced with ICT which makes it innovative in this kind of laboratories for teaching purposes. Besides the hard skills improvements, the laboratory activity aims also at improving the student soft skills in data post elaborations and reporting.

The laboratory functionality and services are not limited only to electrical engineering, but can be also exploited for mechanical engineering, thermal and nuclear engineering. Industrial collaborations are also foreseen in the vision of this laboratory starting from National Instruments and ST Microelectronics. As an improvement, it is already agreed to expand the laboratory hardware towards the power electronics topics ( $a c / d c$ and $a c / d c$ converter).

\section{ACKNOWLEDGMENTS}

The Tommasini's laboratory was funded by the 2016 and 2017 'Fondi per la didattica' funding by Politecnico di Torino. The temporary staff has been recruited thanks a crowdfunding among 23 faculty involved both in the Bachelor and Master Science degree course of Electrical Engineering.

\section{REFERENCES}

[1] The top university rankings, available at http://www.topuniversities.com.

[2] The Joint Committee on Teaching of the Politecnco di Torino (CpD), available at http://www.cpd.polito.it/en/.

[3] B.-M. Block, "Integration of laboratory experiments into introductory electrical engineering courses: concept, implementation and competencebased evaluation," IEEE Global Engineering Education Conference (EDUCON'14), Istanbul, Turkey, 2014, pp. 23-29.

[4] V. Leite, "Innovative Learning in Engineering Education: Experimenting with Short-term Project-oriented Research and Project-based Learning," IEEE International Symposium on Industrial Electronics (ISIE'17), Edinburgh, UK, August 2017, pp. 1555-1560.

[5] T. A. Giuma, P. Holt, and D. Williams, "Multimedia Tools in Electrical Engineering Laboratories," IEEE Bringing Together Education, Science and Technology (Southeastco'96), 1996, pp.529-532.

[6] D. Millard, and G. Burnham, "Innovative interactive media for electrical engineering education," Annual Frontiers in Education Conference. Impact on Engineering and Science Education (Cat. No.01CH37193), Vol.3, 2001, pp. S3C - 17-22.

[7] M. Travassos Valdez, C. Machado Ferreira, and F. P. Maciel Barbosa, "Electrical engineering teaching and distance learning using a desktop virtual reality system," International Universities Power Engineering Conference (UPEC'13), 2013, pp.1-4.

[8] P. Shekhar and M. Borrego, "After the Workshop: A Case Study of PostWorkshop Implementation of Active Learning in an Electrical Engineering Course," in IEEE Transactions on Education, vol. 60, no. 1, pp. 1-7, Feb. 2017. doi: 10.1109/TE.2016.2562611
[9] C. Nwankpa, D. Niebur and K. Miu, "Re-engineering the power engineering class at Drexel," 2001 Power Engineering Society Summer Meeting. Conference Proceedings (Cat. No.01CH37262), Vancouver, BC, Canada, 2001, pp. 1853 vol.3-.doi: 10.1109/PESS.2001.970361

[10] A. Al-Ataby, "Innovative teaching tools for large multicultural cohorts in electrical engineering and electronics," European Workshop on Microelectronics Education (EWME'16), 2016, pp. 1-6.

[11]W. Fischer, and A. Lindemann, "Circuit simulation in a research oriented education of power electronics," Workshop on Control and Modeling for Power Electronics, 2018, pp. 1-5.

[12]O.H. Graven, and Joakim Bjork, "The use of an Arduino pocket lab to increase motivation in Electrical engineering students for programming," IEEE International Conference on Teaching, Assessment, and Learning for Engineering (TALE), 2016, pp. 239-243.

[13]M.C. Alvarez-Herault, A. Labonne, S. Touré, T. Braconnier, V. Debusschere, R. Caire, and N. Hadjsaid, "An Original Smart-Grids Test Bed to Teach Feeder Automation Functions in a Distribution Grid," IEEE Transactions on Power Systems, Vol. 33, No. 1, 2018, pp. 373-358.

[14]M.I. Masoud, "Writing a laboratory report for senior electrical engineering courses: Guidelines and recommendations," IEEE Global Engineering Education Conference (EDUCON'17), 2017, pp. 340-346.

[15] A. Iturregi, E. Mate, D.M. Larruskain, O. Abarrategui, and A. Etxegarai, "Work in progress: Project-based learning for electrical engineering," IEEE Global Eng. Education Conf. (EDUCON), 2017, pp. 464-467.

[16]I. Lilyanova, M. Marinov, and R. Stoianov, "Some aspects of using real and virtual experiment in teaching electrical engineering", International Conference on Electrical Machines, Drives and Power Systems (ELMA), 2017, pp. 185-190.

[17]Y.Y. Nazaruddinand A. Siahaan, "Teaching intelligent control using a laboratory-scaled process mini-plant," IEEE International Symposium on Industrial Electronics (ISIE’17), pp.1567-1572.

[18]M. Rasheduzzaman, B. H. Chowdhury and S. Bhaskara, "Converting an Old Machines Lab Into a Functioning Power Network With a Microgrid for Education," in IEEE Transactions on Power Systems, vol. 29, no. 4, pp. 1952-1962, July 2014.

[19] K. Wachira, and H.O. Absaloms, "A raspberry-pi centred quasi-flipped learning model to trigger creative-thinking in electrical engineering students," IEEE AFRICON'17, 2017, pp.688-693.

[20]C. Fortunato, V. Fernão Pires, and J. F. Martins, "Teaching distribution network protection through the support of a software tool," IEEE International Symposium on Industrial Electronics (ISIE'17), pp.15611566.

[21]A. Estebsari, E. Pons, E. Patti, M. Mengistu, E. Bompard, A. Bahmanyar and S. Jamali,"An IoT realization in an interdepartmental real time simulation lab for distribution system control and management studies," IEEE International Conference on Environment and Electrical Engineering (EEEIC'16), Florence, 2016, pp. 1-6.

[22]Bachelor's degree program in Electrical Engineering, Politecnico di Torino, available on https://didattica.polito.it/laurea/ingegneria_elettrica/ en/presentation.

[23] Master's degree program in Electrical Engineering, Politecnico di Torino, available on https://didattica.polito.it/laurea_magistrale/ingegneria elettrica/en/presentation.

Almalaurea Interview results for graduate students in Electrical Engineering, available on https://didattica.polito.it/portal/pls/portal/ sviluppo.offerta.cdl?p_sdu $=32 \& p \_c d s=35 \& p$ _a_acc $=2018 \&$ p_lang=EN 